\title{
The Africa Regional Sexual and Gender-based Violence Network Annual Partners Meeting: June 26-27 2012, Mombasa, Kenya-meeting report
}

Population Council

Follow this and additional works at: https://knowledgecommons.popcouncil.org/departments_sbsr-rh

Part of the Domestic and Intimate Partner Violence Commons, Health Policy Commons, International Public Health Commons, Maternal and Child Health Commons, Public Health Education and Promotion Commons, and the Women's Health Commons How does access to this work benefit you? Let us know!

\section{Recommended Citation}

Population Council. 2012. "The Africa Regional Sexual and Gender-based Violence Network Annual Partners Meeting: June 26-27 2012, Mombasa, Kenya," meeting report. Nairobi: Population Council. 
The Africa Regional Sexual and

Gender-BAsed Violence Network

MEETING

REPORT

Annual Partners Meeting

JUNE 26-27 2012, MombASA, KenYA

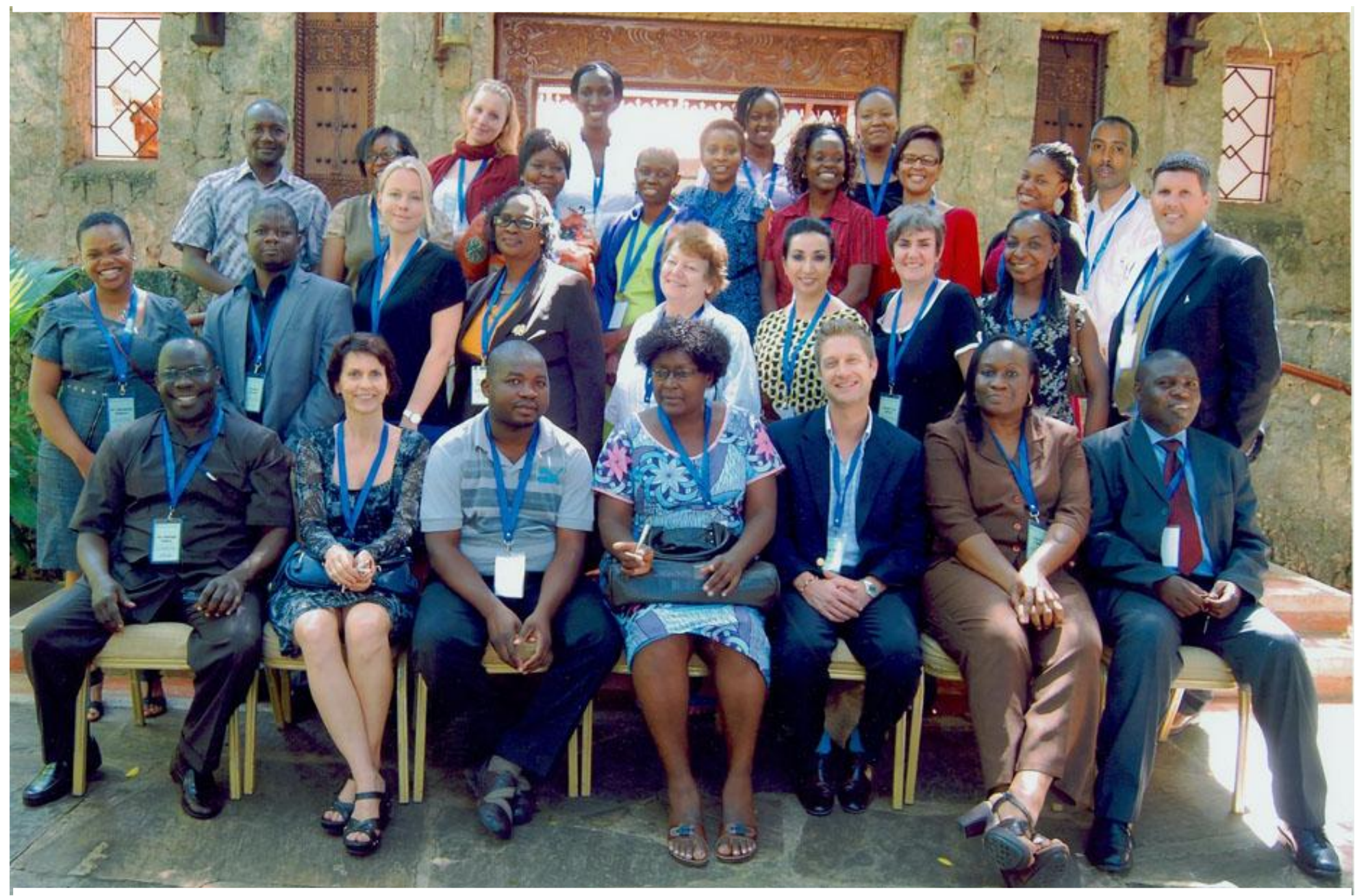

Population Council, Kenya 


\section{The Africa Regional SeXUal ANd Gender-Based Violence NetWork}

\section{Annual Partners Meeting: June 26-27 2012, Mombasa, Kenya}

Population Council, Kenya 


\section{Population Council}

The Population Council confronts critical health and development issues-from stopping the spread of HIV to improving reproductive health and ensuring that young people lead full and productive lives. Through biomedical, social science, and public health research in 50 countries, we work with our partners to deliver solutions that lead to more effective policies, programs, and technologies that improve lives around the world. Established in 1952 and headquartered in New York, the Council is a nongovernmental, nonprofit organization governed by an international board of trustees.

Population Council, Kenya

General Accident House

Ralph Bunche Road

Nairobi, Kenya

www.popcouncil.org

This publication was made possible through support provided by the Regional Swedish-Norwegian HIV and AIDS Team for Africa. The opinions expressed herein are those of the Population Council and do not necessarily reflect the views of the Regional Swedish-Norwegian HIV and AIDS Team for Africa.

Suggested citation: Population Council, Kenya. 2012. The Africa Regional Sexual and Gender-Based Violence Network Annual Partners Meeting: June 26-27 2012, Mombasa, Kenya: Meeting Report. Nairobi: New York. Population Council.

Cover photo by Population Council, Kenya

(C) 2012, The Population Council, Inc.

Any part of this publication may be photocopied without permission from the publisher provided that copies are distributed without charge and that full source citation is provided. The Population Council would appreciate receiving a copy of any materials in which the text is used. 


\section{EXECUTIVE SUMMARY}

From June 26-27, 2012, the Population Council convened an annual partners meeting of its Africa Regional Sexual and Gender-Based Violence (SGBV) Network. Over thirty participants attended, representing program implementing partners, external experts, national governments, regional bodies, and development partners drawn from Kenya, Malawi, Mozambique, South Africa, Swaziland, Tanzania and Zambia.

The objectives of the meeting were: 1) to facilitate South-South technical exchange and informationsharing on the changing landscape of violence among partners, donors, and other experts over the life of the SGBV Network; and 2) to reflect on the ways in which the Network's research is translating into policy and practice. Participants also had the opportunity to showcase and exchange their publications; information, education, and communication materials; advocacy tools; and other materials during the meeting.

This report details the proceedings of the 2012 Africa Regional SGBV Network meeting. It highlights the myriad ways in which activities conducted under this Network have influenced policy, practice, and funding considerations in the region, while detailing the progress of Network partners on their projects, which are built around the following key themes:

- Community-based prevention initiatives

- Strengthening medico-legal linkages

- Innovations in improving health and psychosocial care

- Sexual violence: Services, sentencing and policies.

Through plenary discussions and group work, participants identified a list of action points for entrenching the gains made by the Africa Regional Sexual and Gender-Based Violence Network in regard to SGBV prevention and response efforts across the region. These included:

- Framing the success stories of the Network as an entity, rather than merely as individual projects, in order to take the evidence generated by the Network forward.

- Developing a tool kit that brings together each partner's achievements, and that provides guidance on how these efforts may be adapted by interested parties.

- Continuing the provision of technical assistance by the Population Council to Network partners, and having Network partners engage in South-South technical assistance for any work that will be expanded within or across countries in the region.

Participants widely affirmed the value of the Africa Regional SGBV Network as an efficient, nonduplicative means of generating a coherent body of multi-sectoral evidence on SGBV in the region within a similar time frame. Given the experience it has built up over the years, partners contended that, going forward, the Africa Regional SGBV Network should be considered as a resource to the wider region, with strengths in 1) providing technical assistance in training, research, and influencing policy and practice, 2) replicating responses to SGBV that have been tested by partners, and 3) testing out new, innovative responses to SGBV. 


\section{TABLE OF CONTENTS}

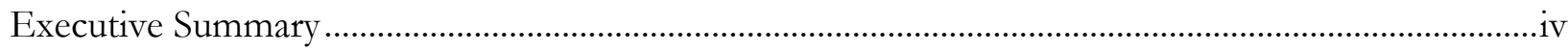

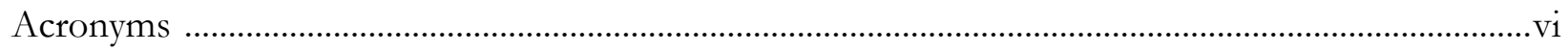

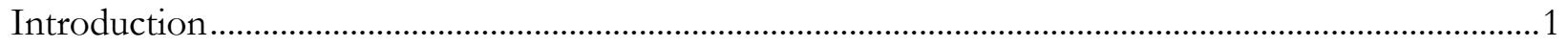

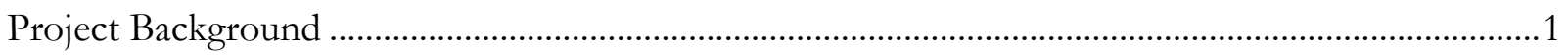

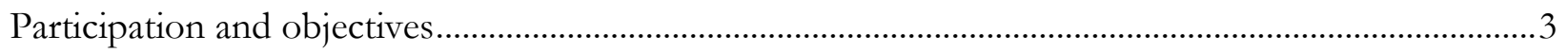

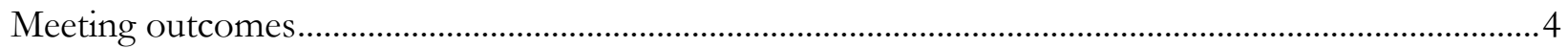

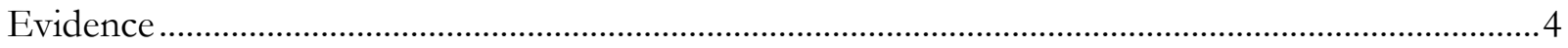

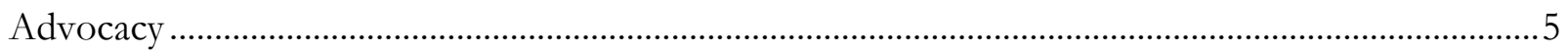

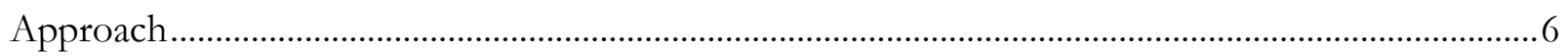

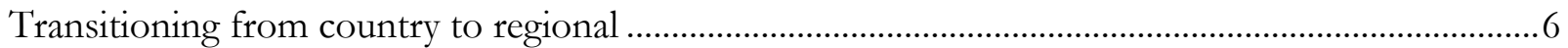

The value of the Africa Regional SGBV Network................................................................................

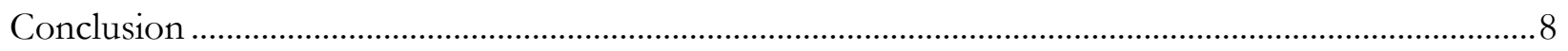

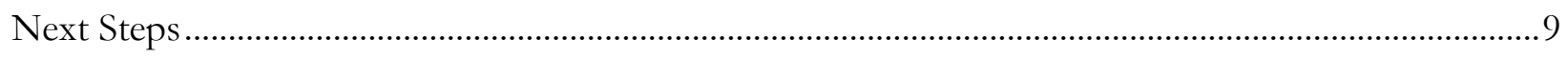

Appendices Appendix 1: Participant List ..............................................................................................

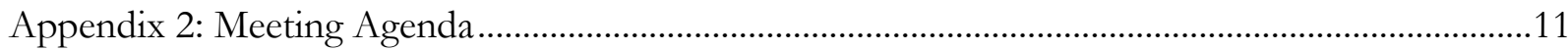

Appendix 3: Summary of Presentations …....................................................................................13

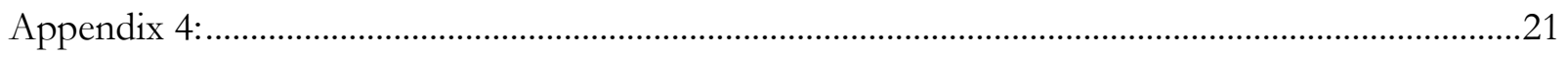

The Africa Regional Sexual and Gender-Based Violence Network: Evidence of Impact...............21 


\section{ACRONYMS}

AIDS

CMIC

DANIDA

DV

EC

EAC

ECSA-HC

GEC

GBV

HIV

IPV

$\mathrm{KNH}$

LSTHM

LVCT

MARPs

MSM

PEP

PEPFAR

PRC

SA

SGBV

SV

SVRI

SWAGAA

TVEP

UNICEF/ ESARO

USAID

UTH

VAC

VSU

ZTVA
Acquired Immune Deficiency Syndrome

Copperbelt Model of Integrated Care (Zambia)

Danish International Development Agency

Domestic Violence

Emergency Contraception

East African Community

East, Central, and Southern Africa Health Community

Girls Empowerment Clubs

Gender-Based Violence

Human Immuno-Deficiency Virus

Intimate Partner Violence

Kenyatta National Hospital

London School of Hygiene and Tropical Medicine

Liverpool VCT, Care and Treatment

Most At-Risk Populations

Men who have Sex with Men

Post-Exposure Prophylaxis for HIV

President's Emergency Plan for AIDS Relief

Post-Rape Care

Sexual Assault

Sexual and Gender-Based Violence

Sexual Violence

Sexual Violence Research Initiative

Swaziland Action Group Against Abuse

Thohoyandou Victim Empowerment Programme

United Nations Children's Fund/ Eastern and Southern Africa Office

United States Agency for International Development

University Teaching Hospital (Zambia)

Violence Against Children

Victim Support Unit

Zero Tolerance Village Alliance 


\section{INTRODUCTION}

\section{Project Background}

Since 2006, the Population Council has provided technical assistance and conducted research to strengthen the evidence base on sexual and gender-based violence (SGBV) programming in subSaharan Africa. An active network of partners from across the region (known as the 'Africa Regional SGBV Network') has emerged as a result of these activities. The partners in question have been developing, implementing and evaluating core elements of a comprehensive, multi-sectoral response model (see Figure 1). While this model incorporates the overlapping and complementary responsibilities of three core sectors (health; police and justice; and social services), and recognizes that survivors require access to all services, it also acknowledges that it may not be feasible, appropriate, or costeffective to deliver all services in one location.

\section{Figure 1: Framework for a comprehensive response to SGBV}

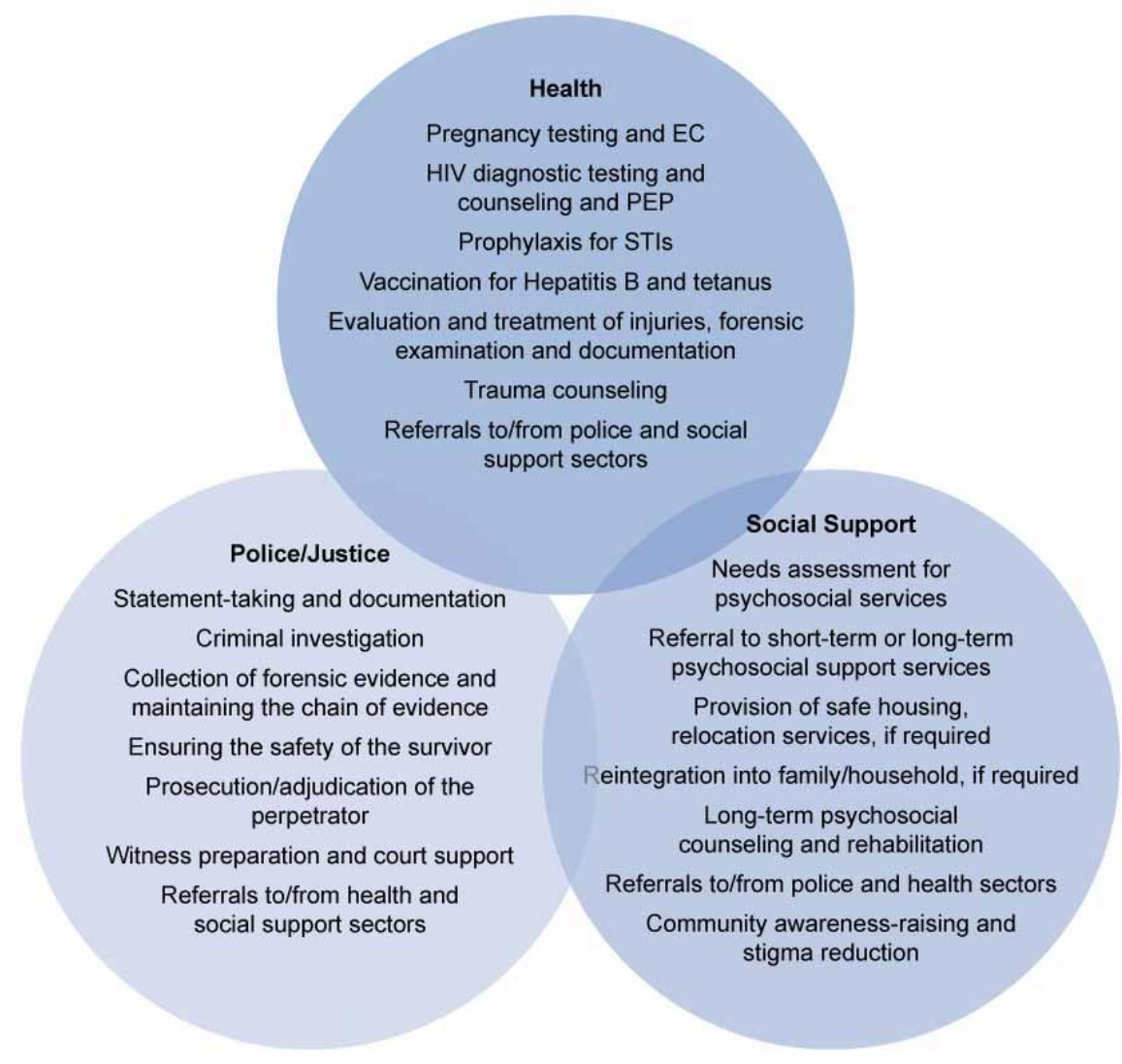

Today, the Africa Regional SGBV Network includes six institutional partners representing five countries and regional bodies that provide technical support to implementing partners. Table 1 provides an overview of the partners and projects currently existing under the Network. Activities of the Africa Regional SGBV Network, funded by the Swedish-Norwegian HIV and AIDS Team for Africa, will continue through 2012. Historically, additional partner activities have also been supported by the United Nations Children's Fund Eastern and Southern Africa Regional Office (UNICEF 
ESARO), the United States Agency for International Development (USAID), the US President's Emergency Plan for AIDS Relief (PEPFAR), and the United Nations Trust Fund for Women through Equality Now.

\begin{tabular}{|c|c|c|}
\hline Country & Project Title & Implementing partners \\
\hline \multirow{2}{*}{ Kenya } & $\begin{array}{l}\text { Improving collection, documentation, and } \\
\text { utilization of medico-legal evidence in Kenya }\end{array}$ & $\begin{array}{l}\text { Liverpool VCT, Care and Treatment (LVCT), } \\
\text { Kenya Ministry of Health }\end{array}$ \\
\hline & $\begin{array}{l}\text { Assessing acceptability and feasibility of } \\
\text { screening for intimate partner violence in } \\
\text { public health care settings in Kenya }\end{array}$ & $\begin{array}{l}\text { Kenyatta National Hospital, Population } \\
\text { Council }\end{array}$ \\
\hline Malawi & $\begin{array}{l}\text { Testing feasibility of police provision of } \\
\text { emergency contraception }\end{array}$ & $\begin{array}{l}\text { Malawi Police Service, Ministry of Health, } \\
\text { Malawi Human Rights Resource Centre } \\
\text { (MHRRC) }\end{array}$ \\
\hline South Africa & $\begin{array}{l}\text { Testing feasibility, impact, and cost- } \\
\text { effectiveness of the Zero-Tolerance Village } \\
\text { Alliance }\end{array}$ & $\begin{array}{l}\text { Thohoyandou Victim Empowerment } \\
\text { Program (TVEP) }\end{array}$ \\
\hline Swaziland & $\begin{array}{l}\text { Testing the feasibility and effectiveness of a } \\
\text { comprehensive SGBV prevention project for } \\
\text { in-school girls in Swaziland; } \\
\text { Developing national guidelines for a multi- } \\
\text { sectoral response }\end{array}$ & $\begin{array}{l}\text { Swaziland Action Group Against Abuse } \\
\text { (SWAGAA) }\end{array}$ \\
\hline Zambia & $\begin{array}{l}\text { Scaling up the Copperbelt Model of } \\
\text { Comprehensive Care (CMIC); Assessing } \\
\text { feasibility of improving PEP access for } \\
\text { sexual violence survivors through Zambian } \\
\text { Police Services }\end{array}$ & $\begin{array}{l}\text { Zambia Ministry of Health, Zambia Police } \\
\text { Service, Population Council }\end{array}$ \\
\hline \multicolumn{3}{|c|}{ South-South technical assistance network partners } \\
\hline & Partner & Activities \\
\hline \multirow{4}{*}{ Regional } & $\begin{array}{l}\text { East, Central and Southern Africa Health } \\
\text { Commission (ECSA) }\end{array}$ & $\begin{array}{l}\text { Intergovernmental health policy body } \\
\text { implementing regional framework on SGBV }\end{array}$ \\
\hline & Population Council, South Africa & $\begin{array}{l}\text { International organization that provides } \\
\text { technical support to partners on SGBV } \\
\text { programming and research }\end{array}$ \\
\hline & Sexual Violence Research Initiative (SVRI) & $\begin{array}{l}\text { International network that promotes } \\
\text { research and training on SGBV }\end{array}$ \\
\hline & $\begin{array}{l}\text { UNICEF Eastern and Southern Africa } \\
\text { Regional Office }\end{array}$ & $\begin{array}{l}\text { Provides technical support to partners on } \\
\text { SGBV programming }\end{array}$ \\
\hline
\end{tabular}

With support from the Swedish-Norwegian HIV and AIDS Team for Africa (from 2009-2012), the Population Council initiated a project to expand the evidence base on comprehensive care for SGBV survivors in sub-Saharan Africa. The specific goal of this effort has been to reduce the incidence and impact of SGBV by strengthening the capacity of medical, legal, and justice sectors to care for SGBV survivors. The approach has also served the larger development objectives of preventing HIV transmission and promoting sexual, reproductive, and human rights. 
As part of this effort, the team of six partners has worked on three main activities: 1) documenting and testing best practices in SGBV service provision; 2) providing South-to-South technical assistance through the network of implementing partners; and 3) influencing policy change and program improvement through broad dissemination to key audiences. The Council has widely disseminated emerging lessons from this program, and has used information generated from partners to contribute to national, regional, and international policy dialogues.

To foster exchange within the Africa Regional SGBV Network, the Council convenes annual meetings for Network members. In this final year of the project, partners under the Network gathered together to consider the impact of their work on policy and practice in their individual countries and wider contexts, and to engage in dialogue with donors and other stakeholders on the changing landscape of SGBV on the continent. The 2012 annual meeting was held in Mombasa, Kenya. This report details the meeting proceedings.

\section{Participation and objectives}

Over 30 participants attended the two-day meeting. Participants represented program implementing partners, external experts, national governments, regional bodies, and donors drawn from Kenya, Tanzania, Malawi, Mozambique, Swaziland, South Africa, Zambia, and the U.S.A (see Appendix 1 for the list of participants).

Two main objectives guided the meeting's agenda:

1. To facilitate South-South technical exchange and information-sharing on the changing landscape of violence among partners, donors, and other experts over the life of the SGBV Network; and

2. To reflect on the ways in which research by the SGBV Network is translating into policy and practice.

The meeting provided an opportunity for participants to share experiences, exchange resources, create linkages for their work, and for partners to showcase the various ways in which their individual work has influenced policy and practice over the life of the Network. The meeting also provided a forum for implementing partners to review the progress of their project implementation.

The meeting was structured around four types of sessions: plenaries, presentations, group discussions and mapping the way forward for the regional partnership (see Appendix 2 for the meeting agenda).

These sessions included:

- Session 1: Community-based prevention initiatives

- Session 2: Strengthening medico-legal linkages

- Session 3a: Innovations in improving health and psychosocial care

- Session 3b: Sexual violence: Services, sentencing and policies

- Session 4: Facilitated Dialogue: An interactive discussion with donors and regional bodies

- Session 5: Participatory Exercise: What sets the SGBV Network apart from a sole institution?

Each session generated active discussion and recommendations for further dialogue and action on key issues. Appendix 3 summarizes each of the presentations. All presentations are available on the Sexual 
Violence Research Initiative website, which hosts the Africa Regional SGBV Network website: http://www.svri.org/africanregionalKen.htm.

The remainder of this report highlights the key themes, discussion points and recommendations offered by participants.

\section{Meeting outcomes}

Electronic communication between participants continued immediately after the meeting, and mainly centered on participants' impressions about the event. Feedback concerning the meeting was extremely positive, with most participants indicating that the meeting was particularly insightful and beneficial for their SGBV work.

Thank you for a wonderful meeting. It introduced a lot of programs and potential which I hope to tap into for the benefit of displaced populations.

-Participant feedback

The pre-determined themes addressed during the sessions and the issues arising from the discussions enabled the participants to reflect on the impact that their work has had on policy and practice in their individual countries at service delivery, national, and international levels, as well as on the ways in which their work has informed funding decisions in the area of sexual and gender-based violence. The presence of donor and regional body representatives, as well as SGBV experts at the meeting, fostered rich discussions and enabled the exploration of opportunities for greater collaboration at national and regional levels - a central goal of the Population Council's South-South technical assistance model.

As detailed in this report, presentations covered a breadth of medical, legal and psychosocial issues associated with SGBV prevention and response activities. As mentioned previously, a common thread running through implementing partner presentations was the impact of each partner's endeavors over the life of the Network. Critical issues that emerged from the discussions are outlined below.

It was really a pleasure and gratifying to be part of this exciting regional event. The meeting gave us such a rich and unique experience. I'm very grateful.

--Participant feedback

Four main, overlapping themes, related to the operations of the Network, emerged from discussions that took place on Day One of the meeting, following partner presentations and facilitated dialogues. The themes that emerged were as follows: evidence, advocacy, approach, and transitioning from country- to regional-level programming. These themes were considered further through group work by implementing partners on Day Two. In addition, an important interactive session between donors and implementing partners was held to reflect on what sets the Africa Regional SGBV Network apart from a 'sole institution' approach in regard to SGBV research and programming.

\section{Evidence}

A key theme of the discussions revolved around the fact that donors require evidence for advocacy, and that the Africa Regional SGBV Network represents an optimal platform for: generating evidence on SGBV in the region, hosting this body of knowledge, and creating visibility around the issue of SGBV. Participants acknowledged that evidence comes in various forms. While evidence can be textual and numerical, it can also take the form of tools, training curricula, and success stories, for example. Over the life of the Network, a mounting body of multiple forms of SGBV evidence has accumulated. A next step for the Network therefore involves packaging this evidence for the utilization of results on a regional scale. 
The modalities for packaging the evidence generated so far by Network partners were explored by participants. Consensus was reached on the need to consolidate the experiences of the Network into an 'advocacy action package' comprising documents such as a small, concise, 'attention-grabbing' publication that shares the experiences of the Network while providing guidance on the future of SGBV work in the region, and a peer review journal article based on the Network.

The need to draw on current information technologies in order to create more visibility around evidence generated by the Network was also highlighted, with discussions ensuing, for example, on the Network using SharePoint, and on launching an 'open source University' type of evidence exchange, involving presentations by Network partners on what works in the response to SGBV, which could be uploaded to You-Tube and made widely available.

Media engagement by Network partners also formed an important part of the discussions on the issue of 'evidence.' Participants stressed the need for Network partners to use the media to create visibility around issues, as opposed to project results solely. Although Network partner projects are currently at different stages of completion, data available from each project is useful for highlighting particular SGBV problems which the media can draw attention to.

Finally, participants stressed the importance of aligning SGBV evidence from the Network to specific donor interests.

\section{Advocacy}

The presentations by partners during this annual meeting created a better understanding among participants of the impressive range of ways in which the Africa Regional SGBV Network is influencing policy and practice in individual countries in the region. A document outlining the various impacts of Network partners' endeavors may be found in Appendix 4.

Given the nature of the evidence now available through the Network, a logical next step for participants was to brainstorm possibilities for advocacy using the existing evidence. A key priority noted by participants was the need to increase the visibility of the Network to donors, government, and the private sector in particular, in addition to other organizations.

Participants agreed on the need to learn lessons in advocacy from the evolution of HIV and AIDS. They envisioned an analysis of the donor and private sector landscape (at local and international levels) as a starting point for this effort. Identifying key, in-country opportunities for disseminating results was also seen as an integral part of this process. Also highlighted was the importance of sensitizing or training media representatives on appropriate reporting of SGBV issues. The idea of bringing celebrities on board to identify with the Network, also formed a part of the discussions.

These discussions dovetailed with intentions for the Network to have partners implement projectspecific communication and advocacy strategies in the year 2012, which will involve promoting engagement with media and local government. The Population Council will provide support to Network partners in the development and implementation of project-specific communication and advocacy strategies, and will provide technical assistance for ensuring greater visibility of their work. 
Noting that the power of networks placed HIV and AIDS firmly on government agendas, participants asserted that, in the context of unstable governments, networks made up of a range of partners that bring different skill-sets to the table are a reliable mainstay for donors.

\section{Approach}

The current approach of the Africa Regional SGBV Network was validated by participants as being ideal given that it enables partners to collectively test and document experiences, develop cost-effective responses to SGBV, and avoid the duplication of effort. The technical assistance that forms an integral part of the Network approach (through proposal and presentation development, remote and on-site support for research and programs, partner exchange learning visits, etc.) was also noted as being particularly useful and a key aspect of the added value that the Network brings.

Donor and regional body representatives at this meeting expressed interest in seeing aspects of the Network approach applied in different settings. There was particular interest, for instance, in: testing out certain Network projects, such as creating a Zero Tolerance Village Alliance and screening for intimate partner violence in clinics in refugee settings (UNHCR); applying lessons learned from the Network to address the SGBV issues of children (UNICEF), refugee populations (UNHCR), and incarcerated populations (UNICEF); exploring how Network partners can use the current Network approach to work together on sexual and reproductive health issues more generally (DANIDA); and in considering South-South technical assistance (particularly learning exchange visits) between the Africa Regional SGBV Network and networks from other sectors such as the police or refugee service providers (UNHCR).

During the discussions, the cost of convening large SGBV meetings emerged as a barrier for some donors. This led to considerations of employing means of virtual exchange under the Network in order to mitigate this potential barrier in the future. Specifically, participants recommended exploring the development of a virtual, interactive mapping/matrix that is accessible to donors and provides a framework of existing organizational structures, services, projects, and goals for future SGBV programs, as well as updates on priority areas for donors, recipients of donor funding, technical experts in various SGBV response areas, and lessons learned from ongoing or completed projects.

A virtual approach was noted as potentially providing several benefits, namely: 1) a clearer portrait of the responses in place to address various SGBV issues of interest, and of the gaps in this regard; 2) better distribution of potential funds, given that the matrix described above would be populated collaboratively with donors and partners to best distribute potential funds, and with skill-sets listed in order for organizations to access technical assistance. It was noted that this virtual approach could potentially serve as a reference point for donors, while also motivating organizations to regularly provide updates on their work, as donors would be able to view progress in real time. Furthermore, it was argued that the approach would be cost-effective, reducing the need to access project sites in person. This virtual approach, if tested, could ultimately become a best practice model for roll-out to other networks.

\section{Transitioning from country to regional}

The replicability of projects carried out under the Network was noted as being critical for donors. The six projects currently being implemented by Network partners across the East and Southern Africa region were each considered by participants as doable and amenable to replication. 
Several possibilities for replication were identified by participants:

- Regional replication of individual project models that have been successfully tested through the Network in a national setting;

- Replicating bybridized versions of existing Network interventions for roll-out across countries;

- Replicating a common intervention, based on tested Network responses that can be piloted regionally;

- Replicating tested Network responses among new populations (e.g., children, refugees) on a regional level;

- Replicating certain aspects of the Network approach regionally (e.g., components of the South-South technical assistance model to continually build capacity and Network strength); and

- Replicating influencing models that Network partners have successfully employed to inform policy and practice regionally.

\section{The value of the Africa Regional SGBV Network}

Lively discussions on the issue of 'What sets the Network apart from a sole institution?' coalesced around one main theme: the South-South learning that occurs under the Africa Regional Sexual and Gender-Based Violence Network. Despite previous discussions around the possible need to explore virtual means of exchange, by the end of this particular discussion, it was clear that the face-to-face forms of South-South interaction characteristic of the Africa SGBV Network were viewed as being unique, and were of paramount importance to partners. Partners cited myriad examples of being inspired to take action in their individual countries after being afforded undistracted time and space to learn about other partners' work (through annual partner meetings, exchange visits, etc.), and to realize what is doable in their own settings.

As examples of how this process has worked in the past, the Malawi Human Rights Resource Center was inspired to test out police provision of emergency contraception during an annual partners meeting where they learned that Zambia Police Services and Zambia Ministry of Health (in collaboration with the Population Council) had successfully carried out this intervention. The Swaziland Action Group Against Abuse is currently leading a consortium of partners in the development of the first national guidelines for a multi-sectoral response to SGBV in Swaziland. This partner embarked on this effort following a partners meeting after being inspired by Network partners in Kenya and Zambia who had successfully developed such guidelines in their own settings. At the end of the June 2012 annual partners meeting in Mombasa, a participant from the Ministry of Health in Tanzania mentioned wanting to replicate the police provision of emergency contraception in Tanzania, seeing it as important and doable after listening to partners' presentations. Furthermore, following this meeting, Population Council South Africa has begun to consider modalities for incorporating GBV/IPV screening into their SGBV work, as a result of lessons learned from Network partner Kenyatta National Hospital. Zambia Police Services (in collaboration with Population Council, Zambia) has also adopted TVEP's case manager model in order to improve the accessibility of SGBV services for sexual violence survivors.

As one participant put it:

There's something about interacting with the Network that inspires partners to push for similar things in their countries after they've compared themselves to other countries. There's more of a 'bow-to' approach with this Network. It's much more practical so that partners are able to benchmark themselves against what's happening regionally - and it's hard to really do that without this sort of 
network structure that we have. Without this Network, one tends to think one is doing enough, [or that] one is doing it right.

In summary, the face-to-face exchanges (including technical assistance among partners, annual partner meetings, partner exchange visits, and other learning opportunities) that are made possible through the Network's approach were seen as setting it apart markedly from other approaches. The Network's approach was also seen as an efficient, non-duplicative means of generating a coherent body of multisectoral evidence on SGBV in the region within a similar time frame. Given the experience it has built up over the years, partners contended that, going forward, the Network should be considered as a resource to the wider region, with strengths in 1) providing technical assistance in influencing policy and practice; training; and research, 2) replicating responses to SGBV that have been tested by partners, and 3) testing out new, innovative responses to SGBV.

These discussions led to reflections on the sustainability of the Network. Several questions around this key issue arose from donors. The questions (presented below) demonstrate that the replication of the Network projects; advocacy; and the expansion of the Network in terms of partners and research/programming areas were seen as core sustainability issues:

- How can the Network help to replicate some of their tested work in other parts of the region?

○ Would the Network consider expanding its number of partners (e.g., to include other organizations conducting good SGBV work)?

- How can we get other donors acquainted with the Network, and on board for funding consideration?

- How can this Network advocate more - i.e., help donors use the Network's evidence to guide governments on what to invest in where SGBV is concerned?

- How can partners engage governments for advocacy?

- How can the network package itself to tap into private sector funding?

- Could we strategically think of current gap areas in the Network and find partners to support these areas?

In response to these questions, Network partners indicated strong willingness to provide technical assistance for the replication of tested work in other countries, and to carefully expand the current number of Network partners, but highlighted the fact that funding would be required to finance both activities. Partners acknowledged the need to develop tools specifically designed to assist donors in advocating on behalf of the Network with other donors and governments, and for the Network itself to employ in publicizing its work among donors (including the private sector). Participants noted that donors could play a role in strategically linking the Network with governments, given that donors typically interact with governments as part of their mandate. Donors could also play an influencing role within existing donor architectures to ensure that SGBV is maintained on the agenda alongside each sector (e.g., health, education, justice, etc.).

\section{CONCLUSION}

The meeting was brought to a close with Network partners inspired to collectively and individually draw on the lessons learned from this meeting to proactively continue to influence SGBV policy and practice in the region. Participants in general left with a realization of the power of evidence in less conventional forms. As a SIDA representative noted, 'Results are not just numbers. How you advance 
the GBV issue on the agenda, how you get other donors on board, and [how you] influence things is also a very important result.'

Noting that the initial objective of the Network was to generate evidence, participants pointed out that evidence around new areas needs to be generated going forward, while old evidence must be used to create conditions for scale-up. As creating these conditions and getting results into policy and practice takes time, a longer-term investment in the Network is needed.

\section{Next Steps}

In a final session, Network partners reflected on the way forward for the Network and on next steps, given the deliberations during the two-day meeting. Through group work, a list of action points was developed for entrenching the gains made by the Africa Regional Sexual and Gender-Based Violence Network in regard to SGBV prevention and response efforts across the region. These included:

- Framing the success stories of the Network as an entity, rather than merely as individual projects in order to take the evidence generated by the Network forward.

- Developing a tool kit that brings together what each partner has been able to do, and outlining how this may be adapted by interested parties.

- Continuing the provision of technical assistance by the Population Council to Network to partners, and having Network partners engage in South-South technical assistance for any work that will be expanded within or across countries. 


\section{APPENDICES}

Appendix 1: Participant List

\begin{tabular}{|c|c|}
\hline Name & Organization \\
\hline 1. Hellen Gesare Bonuke & DANIDA \\
\hline 2. Odongo Odiyo & East, Central, and Southern Africa Health Community \\
\hline 3. Margaret Mak'anyengo & $\begin{array}{l}\text { Gender-Based Violence Recovery Centre, Kenyatta Nat'l } \\
\text { Hospital }\end{array}$ \\
\hline 4. Craig Carty & Independent Consultant \\
\hline 5. Duncan Kwaitana & Kamuzu Central Hospital, Malawi \\
\hline 6. Carol Ajema & Liverpool VCT, Care and Treatment, Kenya \\
\hline 7. Wanjiru Mukoma & Liverpool VCT, Care and Treatment, Kenya \\
\hline 8. Charles Gawani & Malawi Human Rights Resource Center \\
\hline 9. Kennedy Nyambati & Ministry of East African Community, Kenya \\
\hline 10. Martha Rimoy & $\mathrm{MOH}$, Tanzania \\
\hline 11. Elizabeth Eduarda Mulhovo & Gynecologist, Mozambique \\
\hline 12. Adan Isaac & Population Council, Kenya \\
\hline 13. Chi-Chi Undie & Population Council, Kenya \\
\hline 14. Ese Itombra & Population Council, Kenya \\
\hline 15. Harriet Birungi & Population Council, Kenya \\
\hline 16. Stella Etemesi & Population Council, Kenya \\
\hline 17. Winnie Osulah & Population Council, Kenya \\
\hline 18. Linda Van Blerk & Population Council, South Africa \\
\hline 19. Saiqa Mullick & Population Council, South Africa \\
\hline 20. Matt Saxton & Population Council, USA \\
\hline 21. Jessica Price & Population Council, Zambia \\
\hline 22. Mary Zama & Population Council, Zambia \\
\hline 23. Lizle Loots & Sexual Violence Research Initiative \\
\hline 24. Cebile Manzini & Swaziland Action Group Against Abuse \\
\hline 25. Lindiwe Mhlungu & Swaziland Action Group Against Abuse \\
\hline 26. Karolina Kvarnare & Swedish-Norwegian Regional HIV \& AIDS Team for Africa \\
\hline 27. Fiona Nicholson & $\begin{array}{l}\text { The Thohoyandou Victim Empowerment Program, South } \\
\text { Africa }\end{array}$ \\
\hline 28. Gumula Foldrick & $\begin{array}{l}\text { The Thohoyandou Victim Empowerment Program, South } \\
\text { Africa }\end{array}$ \\
\hline 29. Joanina Karugaba & UNHCR \\
\hline 30. Catherine Maternowska & UNICEF/ESARO \\
\hline 31. Tresphord Kasale & Zambia Police Service \\
\hline
\end{tabular}




\section{Africa Regional SGBV Network Partners' Meeting}

June 26-27, 2012

Serena Beach Hotel

Mombasa, Kenya

The Objectives of the meeting are to facilitate South-South technical exchange and information-sharing on:

1. The changing landscape of violence among partners, donors, and other experts over the life of the SGBV Network; and

2. The ways in which research by the SGBV Network is translating into policy and practice.

\begin{tabular}{|l|l|}
\hline \multicolumn{2}{|c|}{ Tuesday, June 26} \\
\hline 8:30-9:30 & $\begin{array}{l}\text { Welcome, introductions: Harriet Birungi, Population Council } \\
\text { Overview of meeting objectives and agenda: Chi-Chi Undie, Population Council Kenya }\end{array}$ \\
\hline 9:30-10:15 & $\begin{array}{c}\text { Session 1: Community-based prevention initiatives } \\
\text { The Zero-tolerance Village Alliance (2010-2012): Fiona Nicholson, Thohoyandou } \\
\text { Victim Empowerment Programme }\end{array}$ \\
& $\begin{array}{l}\text { Testing out the Girls Empowerment Clubs 'Plus' Program in Swaziland: Cebile } \\
\text { Manzini-Henwood \& Lindiwe Mhlungu, Swaziland Action Group Against Abuse }\end{array}$ \\
\hline Questions and discussion
\end{tabular}




\begin{tabular}{|l|l|}
\hline & \multicolumn{1}{|c|}{$\begin{array}{l}\text { Review of Literature on Minimum Sentencing for Sexual Offenses in Sub- } \\
\text { Saharan Africa: Jill Thompson, Independent Consultant } \\
\text { Rape Prevention Policies - A Regional Overview: Lizle Loots, Sexual Violence } \\
\text { Research Initiative }\end{array}$} \\
\hline $12: 45-13: 45$ & \multicolumn{1}{|c|}{ Questions and discussion } \\
\hline $13: 45-15: 00$ & $\begin{array}{l}\text { Session 4: Facilitated Dialogue - An interactive discussion with donors and regional } \\
\text { bodies: Catherine Maternowska, UNICEF ESARO }\end{array}$ \\
\hline $15: 00-15: 45$ & $\begin{array}{l}\text { Session 5: Participatory Exercise - 'What sets the SGBV Network apart from a sole } \\
\text { institution?': Catherine Maternowska, UNICEF/ESARO \& Matt Saxton, Population Council } \\
\text { New York }\end{array}$ \\
\hline $15: 45-16: 15$ & \multicolumn{1}{|c|}{ TEA/COFFEE BREAK } \\
\hline $16: 15-17: 00$ & $\begin{array}{l}\text { Resource Mall: Participants to bring materials to share } \\
\text { END OF WORKSHOP FOR NON-IMPLEMENTING PARTNERS }\end{array}$ \\
\hline
\end{tabular}

\begin{tabular}{|c|c|}
\hline \multicolumn{2}{|r|}{ Wednesday, June 27} \\
\hline 9:00-9:30 & Recap and discussion: Participant \\
\hline \multirow[t]{2}{*}{ 9:30-10:45 } & $\begin{array}{l}\text { IMPLEMENTING PARTNERS-ONLY SESSION } \\
\text { - Discussion and recommendations on the way forward for individual and } \\
\text { collective work under the SGBV Partners Network }\end{array}$ \\
\hline & Facilitators: Chi-Chi Undie \& Catherine Maternowska \\
\hline $10: 45-11: 00$ & TEA / COFFEE BREAK \\
\hline 11:00-13:00 & IMPLEMENTING PARTNERS-ONLY SESSION CONTINUED \\
\hline 13:00- $14: 00$ & LUNCH BREAK \\
\hline \multirow[t]{2}{*}{$14: 00-15: 00$} & Wrap up and Conclusions \\
\hline & Thursday, June 28 \\
\hline 08:15 - 18:00 & Departure \\
\hline
\end{tabular}




\section{Appendix 3: Summary of Presentations}

\section{Session 1: Community-based prevention initiatives}

\section{Thohoyandou Victim Empowerment Programme Limpopo, South Africa, Zero Tolerance Village Alliance: 2010-2012 - Fiona Nicholson, TVEP}

(http://www.svri.org/Presentations/Session1presentation1.pdf)

The Thohoyandou Victim Empowerment Programme (TVEP) has a mission to "generate an attitude of zero tolerance towards all forms of sexual assault, domestic violence, child abuse and AIDS stigmatization in the Thulamela Municipality". TVEP has spent many years informing communities in Thulamela in Limpopo Province in South Africa, on their rights and responsibilities pertaining to sexual assault, domestic violence, child abuse and HIV/AIDS. However, the organization had to face the reality that mere information transfer had not noticeably translated into positive behavior changes and thus the Zero Tolerance Village Alliance (ZTVA) concept was conceived. The ZTVA concept is based on the premise that women and children are more likely to report incidents of Sexual Gender Based Violence (SGBV) and perpetrators are less likely to commit these offences in a community that is fully aware about SGBV and which has taken a public oath of "zero tolerance" towards acts of SGBV.

There are high levels of poverty in the regions where ZTVA works, both according to WHO standards and consensual guidelines. Attitudes toward PLWHA, stigma, gender and SGBV were disappointing, and knowledge of where and how to access support services was largely lacking. After exposure to the ZTVA intervention model, significant increases in VCT uptake, knowledge and understanding of Post Exposure Prophylaxis (PEP) and how it works, knowledge increase on where SGBV centers were located, as well as greater awareness of how to access support services were observed. While the number of those self-reporting SGBV or DV increased in intervention villages, the number of those self-reporting in the control settings actually decreased. These findings, coupled with the qualitative feedback from community stakeholders and those surveyed, show that ZTVA has had a powerful impact on both male and female participants. Many village leaders have requested that they be included in the Alliance - an indication of the acceptance of the ZVTA process within the municipality. The main challenge of scaling up is funding, as the ZTVA model is an intensive process.

TVEP has become instrumental in providing guidance to Departments, such as the South African Police Service (SAPS), that are positioned to deliver services to its client base and those affected. Soon after publishing "No Excuse for Abuse: A History of the Thohoyandou Victim Empowerment Programme,", an ebook that is freely available online, TVEP was contacted by the Department of Social Development who now view the organization as a crucial partner. The Department of Social Services has announced a long term plan to support the scale up and roll-out of TVEP programs. The local SAPS has also become an active partner of 'TVEP's programs, allowing for a more effective and timely response to issues of abuse.

Much has been learned from the ZTVA program, but TVEP recognizes that certain elements of the model need to be strengthened - in particular, the content of the workshops pertaining specifically to women's rights to equality. Further strategies need to be developed to address the patriarchal attitudes

\footnotetext{
${ }^{1}$ http://www.scribd.com/doc/56645559/No-Excuse
} 
inherent in both the men and the women in these communities. It is also clear that the role of the Traditional Leader is critical to the success of the intervention. Overall, however, TVEP believes that the ZTVA model has proven itself to be a success, and would be suitable for roll-out in other African settings facing similar challenges.

The next steps for this project include:

- Integrating the quantitative and qualitative findings into the ZTVA workshops to ensure best practices based upon the gathered evidence;

- Conducting further mapping in the region to support scale-up of ZTVA programming;

- Integrating novel data collection tools into existing programs to inform government and NGO priorities;

- Monitoring and sustaining the existing ZTVA villages by providing support services;

- Promoting and marketing ZTVA to government departments and stakeholders; and

- Seeking additional funding for ongoing support.

\section{Testing the Feasibility and Effectiveness of a Comprehensive SGBV Prevention Project for In-school Girls in Swaziland - Cebile Manzini-Henwood and Lindiwe Mhlungu, SWAGAA}

(http://www.svri.org/Presentations/Session1 presentation2.pdf)

Swaziland is country that is facing a grave fiscal crisis. According to the 2007 Violence Against Children (VAC) study, 69\% of the population is living in poverty and majority of these are women. The country is characterized by acute patriarchy and gender inequality. To add to this, Swaziland has the highest global prevalence of HIV; by $2007,26 \%$ of people aged 15-49 years were living with HIV, and antenatal clinic data (2009) showed that $42 \%$ of pregnant women are HIV positive. Available statistics indicate that women face a disproportionate burden of SGBV and HIV in Swaziland. There is a 31\% lifetime prevalence of SGBV among women aged 15-49. The HIV prevalence among young women is $33 \%$ compared to $17 \%$ among male counterparts (SDHS 2007).

The Swaziland Action Group Against Abuse (SWAGAA) is working to prevent violence against children through Girls Empowerment Clubs (GEC) in schools. While evidence suggests that most SGBV occurs in the home or community, schools are not entirely safe places for girls. About $10 \%$ of girls reported to have experienced sexual violence at school (UNICEF, 2007). In addition 2\% of 13-17 year old girls reported sexual violence by a teacher.

Nearly half of the girls who had experienced sexual violence said that they had told "someone" about the incident, but only one in seven sought legal, medical or social services. The primary reason for not seeking help was that the girl and/or the person she confided in did not realize that the incident was an offence/sexual violence. This is a clear indication of the need for greater awareness-raising and empowerment among young women and girls in Swaziland (UNICEF, 2007).

SWAGAA has pilot tested a Safe Spaces curriculum adapted for a GEC 'Plus' program for adolescent girls aged between 18 to 25 years. A cohort of mentors was trained to lead the GEC Plus with the aim of: improving knowledge and attitudes about the causes of SGBV; increasing the social assets (i.e. friends, social networks) among GEC-Plus participants; increasing the reporting of SGBV cases among GEC-Plus participants; and establishing the feasibility of implementing GEC-Plus in Swaziland through SWAGAA's existing school-based programs and in new sites. 
A survey has been conducted so far among in school girls to establish a baseline against which effects of the GEC Plus intervention will be measured. This project has opened up new exciting possibilities of influencing the Ministry of Education policy using the study evidence. Materials development is underway to address the findings of the baseline survey and will be used to provide evidence to support advocacy for the enactment of the Sexual Offences and Domestic Violence Bill in Swaziland.

\section{Session 2: Strengthening medico-legal linkages}

\section{Assessing the Feasibility of Improving Access to HIV PEP for SV Survivors through Zambia Police Services. Mary Zama, Jessica Price, and Stephanie Topp, Population Council Zambia} (http://www.svri.org/Presentations/Session2presentation1.pdf)

At independence, Zambia already had a law against sexual violence, but it was little was done with it in actual practice. The first important realization towards addressing GBV came in 1994 with the formation of Victim Support Units (VSUs) at police stations. Eleven years later, in 2005, a Gender Division was established in Cabinet. In 2011, the Anti-GBV Bill was enacted into law, while in 2012, further developments have included upgrading the Gender Division into a full Ministry, and the development of the first National Guidelines for the Multidisciplinary Management of Survivors of Gender-Based Violence in Zambia.

In 2011, Population Council, in collaboration with the Zambia Ministry of Health (ZMOH) and the Zambia Police Service (ZPS), began a study to test the feasibility of providing a three-day PEP starter pack to sexual violence survivors through police services at two VSUs in Lusaka. The services are linked to comprehensive follow-up care at Lusaka's University Teaching Hospital (UTH). The study is providing an understanding of the challenges faced in providing PEP services to SV survivors, as well as an understanding of the quality, consistency and coordination of SV services. Through the study, community awareness of and engagement with SGBV services is being created.

Findings from key informant interviews and direct observations indicate that there are several distinct barriers (more than 35) to accessing SV services. These barriers are related to fragmentation and weak coordination between different actors, human resource gaps, and poor infrastructure. Survivors, for example, have to navigate through the maze of services provided by different Ministries and sectors, including the police, medical staff, judiciary and social welfare staff.

To address this, the study has adopted TVEP's case manager model in South Africa. Thus, at least one case manager is made available 24 hours a day and 7 days a week to help a survivor navigate the maze of services. The case manager provides counseling to the survivors, connects her to social services, and provides follows-up through the process up to the legal hearing and reintegration in the community.

The study so far demonstrates the complexities of addressing. Constant supportive supervision, constant advocacy, and constant joint problem-solving with partners have been required so far, resulting in incremental change in institutional cultures.

\section{Testing the Feasibility of Police Provision of EC in Malawi - Charles Gawani, MHRRC}

(http://www.svri.org/Presentations/Malawipresentation.pdf)

The Malawi Human Rights Resource Centre (MHRRC), working in collaboration with the Malawi Police and the Ministry of Health, has been implementing a project to determine the feasibility of using 
trained police officers as first points of contact for sexual assault survivors to safely and effectively provide Emergency Contraception (EC) as a way of broadening access. The project replicates the Copperbelt Model of Integrated Care (CMIC) that was successfully implemented in Zambia under the Network. The project was piloted at Lilongwe and Kanengo police stations, with oversight from Kamuzu Central Hospital.

To implement the project, activities have included: (1) building police officers' capacity to provide EC, (2) analyzing statistical and qualitative data, (3) reviewing VSU statistics, (3) conducting key informant interviews, and (4) disseminating findings.

The project is now at the critical stage of data collection and analysis. So far, the achievements include: getting the Malawi MOH to approve EC provision by police officers, as well as ensuring that sexual assault data is recorded separately from other violence forms by introducing sexual assault logbooks in VSUs.

There is interest from UNFPA and UNICEF in Malawi to join in with SIDA to scale up this project, depending on final study results. Stakeholders in Malawi have also recommended including the provision of PEP by the police, as a component of the intervention.

\section{Improving the collection, documentation and utilization of medico-legal evidence in Kenya - Carol Ajema and Wanjiru Mukoma, LVCT}

(http://www.svri.org/Presentations/Session3apresentation1.pdf)

Although legal instruments addressing sexual violence exist in Kenya, evidence collection rarely occurs according to national guidelines, thus hindering the pursuit of justice. Many health facilities lack the equipment required to undertake evidence collection and, where evidence is collected, the documentation of the collected evidence does not align with the set standards.

Between 2010 and 2012, Liverpool VCT, Care and Treatment (LVCT) conducted a study to address the challenges associated with evidence collection and utilization in Kenya. The study was conducted in health facilities and police stations within two districts and implemented in three phases. The first phase involved collecting baseline information from the two sites and preparatory meetings with key government departments. The second phase focused on developing a locally-assembled rape kit and training the police and health care workers to use the kit, along with existing national protocols to document evidence obtained. In the third phase, LVCT evaluated endline data from the two project sites by reviewing hospital and police records.

The study found that the rape kit reduced the number of reference documents required to be completed for the Post Rape Care (PRC) form and that survivors at the intervention site were three times more likely to have the national police medical record ('P3') form filled in for them both at the health facility and police station (the PRC form is used for recording sexual assault cases within government health facilities, and the P3 form is used for entering sexual assault cases into evidence). The rape kit facilitated faster collection and onward transmission of forensic evidence. Furthermore, the training given to service providers at the intervention sites increased the number of staff competent in evidence collection and documentation. 
LVCT plans to conduct further research to track the paper trail of medico-legal evidence (especially police records), case outcomes within the courts based on health and police records, and to track evidence at police stations for transmission to the Government Chemist.

\section{Session 3a: Innovations in improving health and psychosocial care}

\section{Routine Screening for IPV in public health care settings in Kenya - Margaret Mak'anyengo, Kenyatta National Hospital; Chi-Chi Undie, Population Council Kenya; and Catherine Maternowska, UNICEF}

(http://www.svri.org/Presentations/Session3apresentation1.pdf)

Typically, service delivery models for GBV serve emergency rape or sexual assault needs, but overlook the care of more chronic forms of violence, which intimate partner violence (IPV) represents. Population Council, in conjunction with the Kenyatta National Hospital (KNH), conducted a study to assess the acceptability of IPV screening from the perspective of providers and clients in public health care settings. The overall goal of the study was to expand the access to comprehensive GBV services for women experiencing IPV in Kenya. The study used a primarily qualitative research design involving semi-structured, in-depth interviews with clients and providers, observations of client flow, and collection of service statistics. The antenatal care clinic, the HIV comprehensive care centre, the Gender-Based Violence Recovery Centre, and the Youth Centre of KNH served as the study sites.

Findings from the study indicate the following: ${ }^{2}$

1. There is consensus on the scale of violence among providers and clients alike.

2. Sexual violence is privileged over other forms of GBV. As funding is available for SV initiatives, SV services are provided for free, while clients have to pay for services related to other forms of violence. This inadvertently 'normalizes' other forms of violence.

3. There is a disconnect between provider and client conceptualizations of GBV, with the providers seeing GBV as being synonymous with sexual violence, and clients conceptualizing it in a more comprehensive manner.

4. There is a strong perception among clients that IPV survivors would be more likely to seek help in hospital settings (if asked) than with family or friends.

5. Young people emerged as a special group with slightly different needs from other clients, underlining the important need to provide youth-friendly services for young IPV survivors.

6. Providers expressed a need for GBV/IPV screening in additional health care settings/departments. Nearly half of these proposed screening contact points included the likelihood of capturing youth and children, suggesting the need and importance of exploring screening interventions for this population in the future.

In conclusion, the study found that routine screening for IPV is acceptable to providers and clients at Kenyatta National Hospital. However, to be effective as a routine service, the system as it currently stands needs to be reinforced in specific ways, for example by providing assurance of confidentiality, more positive provider attitudes, and higher respect for clients' rights. Provider training on the various

\footnotetext{
${ }^{2}$ A full report of these findings may be found here: www.popcouncil.org/pdfs/2012RH_APHIAll IntimatePartnerViol.pdf
} 
forms of GBV and on how to handle the screening process is also essential prior to the establishment of any IPV screening intervention.

Informed by these results, an IPV screening intervention is currently being carried out at Kenyatta National Hospital to test the feasibility of this process. Job aids, a provider training curriculum, and a screening tool developed under this program are being used during this feasibility phase.

\section{Session 3b: Sexual violence: Services, sentencing, and policies}

\section{Strengthening Comprehensive Post-rape Care Services in South Africa: Lessons Learned in Achieving Scale and Planning for Sustainability - Saiqa Mullick and Linda Du Plessis, Population Council South Africa}

(http://www.svri.org/Presentations/Session3bpresentation1.pdf)

Sexual assault exposes the survivor to the risk of contracting sexually transmitted infections, HIV infection, and pregnancy. The high incidence of rape and sexual assault in South Africa has made it imperative for the country to provide HIV Post Exposure Prophylaxis (PEP) to rape survivors after sexual exposure. National guidelines for the management of sexual assault were first developed in 2005 and were reviewed in 2008. Furthermore, the National Department of Health has also issued a directive on the provision of PEP to clients who have been exposed either due to condom breakage, and accidental or deliberate non-use of condoms.

Population Council conducted a program to strengthen post-rape care services in South Africa. The program's objectives were to:

- Increase quality of and access to PEP services for sexually assaulted adults and children;

- Strengthen DOH and SAPS, including data management to monitor delivery of PEP, adherence and outcomes;

- Provide support to PEPFAR funded partners on comprehensive delivery of PEP;

- Increase access to PEP for MARPS (Children, MSM, Migrants, Incarcerated Populations);

- Increase awareness and access to PEP for those at risk of occupational exposure;

- Support policy development and implementation in order to increase access to PEP

The program's activities included: conducting advocacy with wide range of stakeholders and establishing strategic partnerships, conducting baseline assessments in district hospitals, training service providers (nurses, doctors, information officers, pharmacists, police), and providing site support.

Baseline assessments indicated that most facilities lacked trained personnel. Policies and guidelines were not universally available. Some sites did not have PEP medication supplies and equipment, and monitoring data was generally unavailable at most sites. Referral systems were not clear or standardized.

A total of 97 sites in 6 provinces were assessed by the program, and 1451 service providers were trained (821 health care workers, 25 operational managers, 18 community health workers, 390 police, and 197 trainers). The program also developed data collection tools, a training manual, a pharmacist tool and job aids (algorithms and fact sheets) as resources to strengthen the system. 
To achieve greater scale, it is recommended that PEP be introduced at lower levels of health care, and low-cost community awareness should be conducted targeting traditional leaders and their constituents. It is also important to document and share best practices, as well as to establish support systems for the service providers trained. It is also recommended that a policy for non-sexual assault PEP be introduced and monitored.

\section{Rape Sentencing Study 2011: Findings, implications and way forward - Jill Thompson, Independent Consultant}

(http://www.svri.org/Presentations/Session3bpresentation3.pdf)

The objectives of this study were to 1) compile and compare the laws relating to sentencing of sexual offences in the Africa region and identify countries which have enacted minimum sentences for rape, defilement and/or sexual assault; 2) compare approaches to minimum sentencing across the region; and 3) consider the application and efficacy of minimum sentences as a strategy in sexual offences cases based on the experience of other countries around the world.

Findings from this desk review based on relevant legislation from 12 countries in East, Central, and Southern Africa, indicate that 11 out of the 12 countries have amended Sexual Offences Laws in past 15 years, and 9 of the 12 have enacted minimum sentences for rape and/or child rape/defilement. Furthermore, countries have adopted a wide range of approaches to establishing the severity of sentences for rape ranges, from no minimum to minimum life imprisonment.

Few countries outside Africa have mandatory minimums for sexual offences. Indeed, the trend is steering away from minimum sentencing toward detailed sentencing guidelines, as minimum sentences do not deter crime where risk of reporting/conviction is low.

Conclusions from this desk review are as follows:

- Sentences for sexual offences should be consistent and proportionate. Although data is limited, research from South Africa and elsewhere suggests that some of the sentencing approaches adopted in Africa will not achieve this.

- Recommended approach: lower minimum sentence increased for aggravating circumstances. High maximum.

- Limit judicial discretion to mitigate; disallow mitigation based on rape stereotypes

- Sentencing guidelines are needed where not explicit in legislation. 


\section{National Rape Prevention Policies: A Regional Overview - Lizle Loots, SVRI}

(http://www.svri.org/Presentations/MombasaRegionalPreventionPolicies.pdf)

The Sexual Violence Research Initiative (SVRI) has conducted an extensive review of national rape prevention policies. This review aims to:

1. Identify and critique best practice in rape prevention policy globally, and to

2. Assess national policies from the African region

A literature search covering 192 countries found 173 policies. When these policies were scanned against inclusion criteria, 49 were excluded for not meeting the criteria, while 142 policies from 110 countries were found to be relevant. Of these, 7 addressed sexual violence, 17 applied to domestic violence, 27 applied to GBV, 42 to gender equality, while 32 addressed rape.

Of the 33 policies that address rape, 19 policies are from the African region. Six of the 19 policies addressed rape as a clear issue of concern. The policies from Africa came from six countries: Ethiopia, Liberia, Rwanda, South Africa, Tanzania and Zambia.

Each policy was analyzed using a structured questionnaire (guided by WHO/LSHTM, 2010) which looked at: the policy focus, sector driving plan, level of prevention (primary, secondary, tertiary), action plan, identified effective programs, training needs identified, budget plans, and monitoring and evaluation plans.

On examining which sectors drive the policies, the study found that five policies came from Gender Divisions, while one policy was from the Department of Health (South Africa). All policies had a Plan of Action, with a description of activities, four countries had timeframes attached to activities, three countries had budget plans and allocation of funds, and Rwanda and Zambia had M\&E plans with indicators.

The review of the African policies revealed that only one-third of policies discussed rape (similar to the global review) and that primary prevention and prevention of burn-out of service providers receive little attention. All policies are situated in Women's Directorates except in for South Africa where the policy is health-focused.

The recommendations from this review are that:

- Advocacy for the inclusion of rape prevention is needed;

- Operational definitions should be developed and disseminated;

- Best practices should be identified, evaluated and built upon;

- Policies must include comprehensive M\&E;

- Needs of survivors must take priority, and service providers should supported and mentored;

- Prevention interventions guided by the evidence should be developed multi-sectorally. 
Appendix 4:

The Africa Regional Sexual and Gender-Based Violence Network:

Evidence of Impact

\section{KENYA}

\section{Partners: Kenyatta National Hospital (KNH) and the Population Council}

Project synopsis: This project involves testing the acceptability and feasibility of routine screening, referral, and response for intimate partner violence (IPV) in public health care settings in Kenya.

Policy/practice impact at the service delivery level

- Through this project, education and awareness-raising around SGBV has occurred broadly throughout $\mathrm{KNH}$ (the largest public referral hospital in the East African region) via multiple provider training sessions in various departments (total \# trained so far $=125$ ).

- As a result of this study, the SGBV survivor in-take form at $\mathrm{KNH}$ now includes intimate partner violence screening questions.

- Under this project, a multi-departmental intimate partner violence taskforce was formed to guide the study, comprising representatives from KNH's antenatal care, HIV comprehensive care, youth center, and Gender-Based Violence Recovery Center clinics.

- The Gender Technical Working Group of the Division of Reproductive Health (Ministry of Health) has recommended that IPV screening be piloted in other hospitals.

\section{Policy/practice impact at the national level}

- Findings from Phase I of this study have prompted Kenya's Division of Reproductive Health (within the Ministry of Health) to contact the Population Council to discuss incorporating routine screening for intimate partner violence in the national Standard Operating Procedures for SGBV management, and in the national guidelines for the medical management of survivors of sexual violence.

- Sections from the IPV screening provider training manual developed under this project are being adapted for inclusion as part of the latest national Training Manual on Clinical Management of Survivors of Survivors of Sexual Violence in Kenya.

$\circ$ The partnership with $\mathrm{KNH}$ on this project (and the recent, keen interest of the Ministry of Health) provides strong potential for IPV screening to be rolled down to district/county levels.

- The Population Council has played a key role in helping to form a collective of East Africabased scholars working on intimate partner violence screening to strategically target high-impact regional and international conferences with panel presentations based on evidence emerging from this under-explored area. Scholars within this collective will be giving a panel presentation on IPV screening at the WHO, Gates Foundation, and Center for AIDS Research-sponsored Integration for Impact international conference in Nairobi in September 2012 (http://integration2012.org/). 
Policy/practice impact at the international level

○ The World Health Organization (WHO) is currently setting guidelines around routine screening for IPV in developing countries. Evidence from this project, and from the work of other scholars in the East African collective mentioned above, is helping to shape the final guidelines.

- 1 study report published, based on Part I of this work

○ 1 paper submitted to, and currently under review by, an international, peer-review journal

○ 4 papers presented at international conferences; 1 paper presented at a national conference

Additional funding raised

- Funding in the amount of USD 250,000 was leveraged from USAID/Kenya to carry out Phase I of this project.

\section{Partner: Liverpool VCT, Care and Treatment (LVCT)}

Project synopsis: This project involves testing the feasibility of a strategy for improving the collection, documentation and utilization of medico-legal evidence across police stations and health facilities.

\section{Policy/practice impact at the service delivery level}

- Through this project, LVCT has developed a model for collaborative health care provider capacity-building involving the Department of Police, the Department of Public Prosecution, and the Government Chemist. This multi-sectoral training approach has since been adopted by Kenya's Sexual Offences Act Task Force.

- Nationally, LVCT has provided leadership in the implementation of the multi-sectoral training approach for community opinion leaders, the police, and health care providers.

- The locally-assembled rape kit developed under this project is the only rape kit available in public health facilities in the country.

- Information, Education, and Communication (IEC) materials developed by LVCT under this project are currently in use within government health facilities - for example:

- A checklist for the documentation of evidence collection

- A brochure and poster entitled "Sexual violence: If it happens"

- A poster on guidelines for documentation of medico-legal examinations

\section{Policy/practice impact at the national level}

- The national police medical record form and post-rape care (PRC) form (the former is used for entering sexual assault cases into evidence, and the latter is used for recording sexual assault cases within government health facilities) have been revised using evidence from this study. The new PRC form is expected to be gazetted in 2012.

- Selected courts in the country have also accepted the PRC form as an official evidence document to be used in presenting evidence during prosecutions.

- The Division of Reproductive Health (DRH) within the Ministry of Health has adopted key findings from the two phases of this study

- The use of the rape kits on a national scale is currently being pursued, with the DRH sourcing for these kits within the Government of Kenya's commodity supply system. 
- The national guidelines for the management of sexual violence, and the national training curricula on the clinical management of sexual violence survivors are currently being reviewed with a view to including new evidence from this study.

- Kenya's Sexual Offences Act Task Force is currently developing Standard Operating Procedures. LVCT is participating in this important process, and is in charge of writing a section on evidence collection and management, based on lessons learned from this study.

- Findings from this study informed a review by LVCT of medical regulations for implementing Kenya's Sexual Offences Act. The finalized review has since been handed over to Kenya's Attorney General.

\section{Policy/practice impact at the international level}

- 1 paper based on this work published in the Journal of Forensic Medicine

- 1 study report published, based on Part I of this work

- 1 study report to be published in July 2012 based on Part II of this work

○ 2 papers presented at international conferences

\section{Additional funding raised}

- A three-year 3 year United Nations Trust Fund grant focused on referral mechanisms for evidence across sectors

- A grant from the Elton John AIDS Foundation aimed at establishing a quality assurance framework for post-rape care services

\section{MALAWI}

\section{Partners: Malawi Human Rights Resource Center, Malawi Police Service, Ministry of Health}

Project synopsis: This project involves determining the feasibility of replicating the Zambian model (developed under this Network) of police provision of emergency contraception to sexual assault survivors in other national contexts - specifically, in Malawi.

\section{Policy/practice impact at the service delivery level}

$\circ$ Through this project, log books dedicated to recording information on sexual assault survivors specifically have been introduced within several Victim Support Units in Malawi.

\section{Policy/practice impact at the national level}

○ The Ministry of Health headquarters has given approval for the police to administer EC in Malawi and has asked MHRRC to roll out this program.

- MHRRC has impacted other partners that form part of this project's regular stakeholder meetings. One such partner is UNICEF Malawi (which is setting up one-stop centers (OSC) for SGBV in Malawi), which has incorporated police provision of EC into their OSC model.

- As findings from this project indicated that transporting survivors from the police station to the hospital proved to be a major barrier, UNICEF has now bought a vehicle for transporting anticipated sexual violence survivors that report to the police station first (to facilitate their forthcoming OSC model). 
Policy/practice impact at the international level

- As part of the South-South technical assistance component of this project, MHRRC received training from South Africa's Medical Research Council (MRC) on the modalities of training health providers and police for this project. The training materials used by MRC have since been adapted for developing the OSC guidelines in Malawi.

1 paper presented at an international conference

\section{Additional funding raised}

- MHRRC has secured funds (approximately USD 1.3 million Malawi Kwacha) from the Royal Norwegian Embassy for a wider project which will involve police provision of EC.

\section{SOUTH AFRICA}

\section{Partner: Thohoyandou Victim Empowerment Programme (TVEP)}

Project synopsis: This project involves testing the feasibility and effect of a 'Zero Tolerance Village Alliance' concept, geared toward mobilizing communities to take a stand against violence through educational workshops, dialogues, and campaigns at the community level, and culminating in a traditional pledge-taking ceremony (against GBV) by traditional ruler and other men in the community.

\section{Policy/practice impact at the service delivery level}

- Over the life of this project, TVEP has become instrumental in providing guidance to the Departments within the South African government that are positioned to deliver services to TVEP's client base. The Department of Social Development in particular regards TVEP as an integral part of their policy and programming agenda.

- Since the completion of the TVEP intervention, many traditional leaders and village elders in South Africa have requested that they and their villages be included in the Zero Tolerance Village Alliance.

Policy/practice impact at the national level

- The South African Provincial Government has committed to providing assistance in raising funds for TVEP to scale up and roll out TVEP's Zero Tolerance Village Alliance model. Their attention was drawn to TVEP after the publication TVEP's Network-funded e-book (entitled No Excuse for Abuse: A History of the Thohoyandou Victim Empowerment Program) - the only full documentation of the organization's work to date - and after the closing ceremonies of TVEP's Zero Tolerance Villages, attended by many government officials.

Policy/practice impact at the international level

○ 1 publication that documents TVEP's history and evolution in program strategy, implementation lessons, and areas for future development. This is the only full documentation of TVEP's work to date and is expected to serve as an important knowledge management, planning, and fundraising tool for the organization.

○ 1 study report published

- 2 papers presented at international conferences 


\section{Additional funding raised}

O Recent project results prompted the Joint Gender Fund to provide funding to TVEP to run their intervention in two additional villages.

- Irish Aid has funded TVEP to train 5 community-based organizations in the the Zero Tolerance Village Alliance methodology, at the request of the Government of South Africa's Dept. of Social Development.

\section{SWAZILAND}

\section{Partner: Swaziland Action Group Against Abuse (SWAGAA)}

Project synopsis: This project involves two key activities, 1) the development of national guidelines for a multi-sectoral response to SGBV in Swaziland, and 2) testing the feasibility and effect of a comprehensive SGBV prevention project for in-school girls in Swaziland.

Under the Network (and following in the footsteps of Network partners in Kenya and Zambia), SWAGAA is also taking the lead in Swaziland in developing the country's first ever National Multisectoral Guidelines for the Management of Sexual Violence Cases. They are being supported in this effort by a coordinating committee comprising government institutions and other key nongovernmental organizations.

SWAGAA is the newest partner to join to Network and they are, thus, currently in the early stages of implementing their SGBV work with in-school girls. Findings from a recently completed baseline survey of in-school girls indicate the following:

- Sexual abuse in school is viewed as common by $42 \%$ of respondents

○ Inappropriate touching was cited as the most common kind of in-school sexual violence against girls

- $23 \%$ had ever heard of a school girl that was forced to have sex with a teacher

○ $5 \%$ had been forced to have sex by their fellow schoolmate

○ $41 \%$ had either steady or non-steady partners

○ $60 \%$ reported having friends in their neighborhood

- $87 \%$ had someone to turn to during difficult times

- 56\% were of the opinion that a pregnant girl should not be allowed to remain in school, while $7 \%$ were not sure

It is anticipated that findings from the final evaluation will be used to inform programming and policies within the Ministry of Education.

\section{ZAMBIA}

\section{Partners: Zambia Police Services (ZPS), Ministry of Health, and the Population Council}

Project synopsis:

This project involves 1) the national scale-up and institutionalization of the previously tested model of police provision of emergency contraception (EC) in Zambia, and 2) assessing the feasibility of improving post-exposure prophylaxis (PEP) access for sexual violence survivors through the Zambia Police Services. 
Policy/practice impact at the service delivery level

O During Phase I of this project, police were trained to provide EC to survivors of sexual violence that report their cases at police stations. The project contributed to the development of national service delivery protocols for clinical care and police response to sexual assault.

- Under Phase II, the Council is supporting the Zambian government's scale up and institutionalization of police provision of EC.

- Under this project, a multi-sectoral SGBV sub-committee under the Ministry of Health's Safe Motherhood Technical Working group was formed, comprising representatives from the Ministry of Health, ZPS Victim Support Unit, ZPS Medical Unit, Chainama Hospital, and the University Teaching Hospital.

- The success of the police provision of EC project led government officials to request support from the Council in piloting police provision of post-exposure prophylaxis (PEP) for HIV (for sexual assault survivors). This is the focus of the Council's work in this final phase of the project.

- Under this project, substantial support has been provided for operationalizing the multi-sectoral policy on SGBV, resulting in better integration of different sectors/partners in Zambia.

Policy/practice impact at the national level

- Through this work, the Council has been able to get both medical and justice sectors in Zambia to acknowledge and accept EC provision at police stations. This tremendous policy accomplishment helped set the stage for the development of the national guidelines (see bullet below) and roll-out.

- The first draft of the National Guidelines for the Multidisciplinary Management of Survivors of GBV in Zambia was actually a document developed by the Population Council under Phase I of this project in 2007. The Zambian government realized the importance of this endeavor and asked that the Council assist with developing the document into national guidance. In May 2012, the guidelines were officially adopted by the government. Importantly, these national guidelines actively embrace the comprehensive model of care that has been continuously promoted under this SIDA project, and they allow for police provision of EC, an innovative model that the Council introduced, piloted, and is now scaling up.

- Results from the police provision of EC project led Zambian officials to request that the Council scale up and institutionalize this project nationally, and this scale-up process has occurred since then.

\section{Policy/practice impact at the international level}

- The police provision of EC model has been shared globally, and is now being replicated in Malawi under this Network, but also independently by other organizations in Malawi.

- 1 study report published, based on Part I of this work

- 2 papers presented at international conferences 